\title{
Risk and protective factors distinguishing profiles of adolescent peer and dating violence perpetration
}

\author{
Vangie A. Foshee, PhD ${ }^{\mathrm{a}}$, Heath Luz McNaughton Reyes, MPH ${ }^{\mathrm{a}}$, Susan T. Ennett, $\mathrm{PhD}^{\mathrm{a}}$, \\ Chirayath Suchindran, $\mathbf{P h D}^{\mathrm{b}}$, Jasmine P. Mathias, $\mathbf{M P H}^{\mathrm{b}}$, Katherine J. Karriker-Jaffe, $\mathbf{P h D}^{\mathrm{a}}$, \\ Karl E. Bauman, $\mathrm{PhD}^{\mathrm{a}}$, and Thad S. Benefield, $\mathbf{M S}^{\mathrm{b}}$ \\ aDepartment of Health Behavior and Health Education, Gillings School of Global Public Health, \\ University of North Carolina at Chapel Hill \\ bDepartment of Biostatistics, Gillings School of Global Public Health, University of North Carolina \\ at Chapel Hill
}

\section{INTRODUCTION}

Adult studies suggest that some violent individuals generalize their violence to multiple targets, whereas others direct their violence against only one type of target. This research has focused primarily on characteristics that distinguish adult male batterers who use violence against only their intimate partners from those who generalize their violence to others, the latter of which have higher risk profiles and engage in more severe violence [17]. Despite these findings, little research has been done with adolescents to define violence profiles based on whether violence is used against multiple targets or limited to certain targets, or to identify characteristics that distinguish violence profiles. That is the focus of the current study.

Only two studies have defined adolescent violence profiles or typologies based on the overlap in violence against dates and others. The first was conducted with high risk boys living in poor urban minority communities [8]. Participants were categorized into four groups created by the cross-classification of street and dating violence. Poor family relationships and weak parenting skills distinguished boys who perpetrated both types of violence from boys who perpetrated either or neither type. The second study, also with highrisk adolescents, created typologies based on cluster analyses of multiple types of peer and dating violence perpetration and victimization and suicidal behaviors [9]. Multiple clusters of behaviors were identified but neither risk nor protective factors distinguishing cluster membership were examined.

(C) 2010 Society of Adolescent Health and Medicine. All rights reserved.

Corresponding author: Vangie Foshee, Ph.D., Professor, Department of Health Behavior and Health Education, 319B Rosenau Hall CB\# 7440, Gillings School of Global Public Health, University of North Carolina at Chapel Hill, Chapel Hill, North Carolina, 27599-7400. Telephone 919-966-6616, Fax 919-966-2921, foshee@email.unc.edu.

Publisher's Disclaimer: This is a PDF file of an unedited manuscript that has been accepted for publication. As a service to our customers we are providing this early version of the manuscript. The manuscript will undergo copyediting, typesetting, and review of the resulting proof before it is published in its final citable form. Please note that during the production process errors may be discovered which could affect the content, and all legal disclaimers that apply to the journal pertain. 
The current study extends research in this area by examining risk and protective factors from multiple domains that could distinguish violence profiles using a general sample of boys and girls living in rural areas. We define four violence profiles based on whether adolescents used violence against both peers and dates, against dates but not peers, against peers but not dates, or no violence against peers and dates and examine risk and protective factors that distinguish profiles. We determine whether individual attributes and behaviors and factors from four social domains key to adolescents (the family, peer, school, and neighborhood context) are associated with violence profiles. We also determine which domain is most important in distinguishing profile type. Risk factors in each social domain are conceptualized from a social learning theory perspective and protective factors are conceptualized from a social control perspective because these are the two most supported theories in research on adolescent risk behaviors. Finally, we determine if there are sex differences in the risk and protective factors distinguishing profile membership because it now is well established that violence perpetrated by girls toward peers and dates is common $[10,11]$ and associated with serious long-term consequences [12].

Based on social learning theory [13], we determine if exposure to models of deviant behavior in each of the four social domains distinguishes profile membership. Social control theory posits that a tendency for deviance is universally shared but that conventional controls can constrain deviant behavior [14-15] and thus be a protective factor against risky behavior. Parental monitoring [16], peer disapproval of deviant behaviors [17], school bonding or connectedness [18], and neighborhood informal social control [19] have each been conceptualized from a social control perspective as constraints on adolescent deviant behaviors and are examined here as potential protective factors. The individual risk factors examined include psychological attributes and substance use because they have been associated with both peer [20,21] and dating violence [11]. The protective factors examined from that domain include academic performance, which has been negatively associated with peer and dating violence [21,22], and social bonding, which has been conceptualized from a social control perspective [15].

We hypothesize that for both boys and girls, the likelihood that an adolescent will use both compared to only one or neither type of violence will increase as the risk factor scores increase and the protective factor scores decrease. Each of the risk and protective factors examined are amenable to change and could be targeted in interventions for preventing both peer and dating violence at multiple levels of the socioecological framework.

\section{METHODS}

Adolescents in the eighth through tenth grades in the public schools in three nonmetropolitan counties in North Carolina completed self-administered questionnaires in school in fall 2003 and also in the spring 2004. Parents had the opportunity to refuse consent for their child's participation by returning a written form or by calling a toll-free telephone number. The Institutional Review Board for the School of Public Health at the University of North Carolina at Chapel Hill approved the data collection protocols. 
In the fall of 2003, 79\% ( $\mathrm{n}=5017)$ of the 6342 eligible students completed a survey. Of these, $85 \%(n=4266)$ also completed a survey in the spring of 2004. The analytic sample was restricted to participants who completed a survey at both waves who were not missing data on race $(2 \%, \mathrm{n}=104)$ or grade $(\mathrm{n}=2)$ and who reported at either assessment that they had ever been on a date $(n=2,907)$; those who had not dated would not have had the opportunity to use dating violence. The percentage of eighth, ninth, and tenth graders who had ever been on a date was $65 \%, 71 \%$, and $79 \%$, respectively. The sample is $52.9 \%$ female; $59.4 \%$ white, $30.0 \%$ black and $10.7 \%$ of another race/ethnicity; $7.9 \%, 57.2 \%$, and $34.9 \%$ have parents with low, medium, and high education levels respectively; and $68.8 \%$ live in a two-parent household.

\section{Measures}

Violence profiles-Dating violence perpetration was assessed at each of the two waves using a short version of the Safe Dates Physical Violence Perpetration Scale [23,24]. Adolescents were asked "During the past three months, how many times did you do each of the following things to someone you were dating or on a date with? Don't count it if you did it in self-defense or play?" The items included: 1) slapped or scratched them, 2) physically twisted their arm or bent back their fingers, 3) pushed, grabbed, shoved, or kicked them, 4) hit them with your fist or with something else hard, 5) beat them up, and 6) assaulted them with a knife or gun. Response options ranged from none to 10 or more times. A continuous score representing the amount of dating violence perpetrated was created by summing responses across the two waves. A dichotomous dating violence variable was created with 1 indicating perpetration of at least one dating violence act at either assessment and 0 indicating no perpetration of dating violence at either assessment. Peer violence perpetration was similarly assessed with the question "During the past three months, about how many times have you done each of the following things to someone about the same age as you that you were not dating?" The same six items were listed, and the same methods were used to create continuous and dichotomous peer violence perpetration variables.

Based on the two dichotomous variables, a nominal outcome variable with four categories representing the violence profiles was created: both peer and dating violence perpetrator (Both), dating violence perpetrator only (DV Only), peer violence perpetrator only (PV Only), and neither (Neither). We used measures from both the fall and spring questionnaires to create the profiles so that we could capture violent behaviors perpetrated across a sixmonth period, as opposed to only three months, to decrease chances of misclassifying profile membership.

Concurrent risk and protective variables-Risk and protective factors from the five domains, described in Table 1, were summed across the two assessment waves. All variables were mean centered to reduce multicollinearity and enable probing of significant interactions.

All constructs were measured by self-report, except for two of the peer context variables, "number of friends using dating violence," and "number of friends using peer violence," which were assessed using sociometric methods. On the questionnaires, adolescents 
identified up to five friends using identification numbers from a student roster. The adolescent's friendship network was defined as those school friends identified by the respondent and who identified the respondent as a friend. Because the respondent's friends in school were included in data collection, the friends' reports of violence, rather than the respondent's perceptions, were used to create the two variables about friend use of violence.

\section{Analysis Strategy}

Although the amount of missing data was small (less than $10 \%$ missing on any independent variable), multiple imputation using SAS PROC MI and SAS PROC MIANALYZE [25] was performed to replace missing values. Five sets of missing values were imputed using multiple chain Marcov Chain Monte Carlo methods. As recommended by Allison [26], our imputation strategy involved stratifying the sample by sex, imputing separately for each group and recombining the samples prior to analysis. All of the predictors used in each of the domain specific models (including the demographic variables) were included in the imputation model.

Multinomial logistic regression was used to determine if the likelihood of an adolescent being in the Both profile compared to the DV Only, PV Only, or Neither profile could be predicted from the risk and protective factors. The choice of a reference category is important to the interpretation of results. Our hypothesis specifies the Both profile as the reference category. For convenience of presentation, odds ratios are inverted so that for the hypothesis to be supported the odds of being in the Both profile compared to the other profiles increase as the risk score increases and decrease as the protective factors increase. For example, an odds ratio of .50 for a protective factor when predicting the Both verses Neither profile indicates that a one unit increase in the protective factor reduces the odds of involvement in the Both compared to the Neither profile by $50 \%$ and an odds ratio of 1.20 for a risk factor indicates that a one unit increase in the risk factor increases the odds of involvement in the Both compared to the Neither profile by $20 \%$.

Separate multinomial regression models were estimated for each of the five domains, controlling for demographics. The multivariate Wald test was used to determine if, for each domain, the set of interactions between sex and each risk and protective factor contributed significantly to the model. If the Wald test was not significant at $a=.05$ we dropped all of the interaction terms. Otherwise, we retained significant interaction terms and probed them using post-hoc analyses for logistic regression. The max-rescaled pseudo $\mathrm{R}^{2}$ and the Bayes Information Criterion (BIC) goodness-of-fit statistics were used to compare domain-specific models. The max- rescaled pseudo $\mathrm{R}^{2}$ ranges from 0 to 1 and behaves like the linear model $\mathrm{R}^{2}$ in that higher values indicate better model fit. The smaller the BIC the better the model fit.

\section{RESULTS}

\section{Prevalence of Profile Membership by Sex}

As shown in Table 2, significantly more girls (16.73\%) than boys (7.72\%) are in the Both profile and significantly more girls $(5.73 \%)$ than boys $(2.06 \%)$ are in the DV Only profile. 
There are no significant sex differences in the prevalence of the PV Only and Neither profiles.

Both boys and girls in the Both profile reported using significantly more peer and dating violence than those in the PV Only $(\mathrm{t}=-22.36)$ or DV Only $(\mathrm{t}=-8.30)$ profiles. Within each violence profile, boys reported using significantly more of the designated violence than girls (DV Only: $\mathrm{t}=4.16, \mathrm{p}<.001 ;$ PV Only: $\mathrm{t}=10.39, \mathrm{p}<.001$; Both (DV perpetration): $\mathrm{t}=$ 17.52, $\mathrm{p}<.001$; Both (PV perpetration): $\mathrm{t}=15.02, \mathrm{p}<.001$ ). The pattern of sex differences within profiles differed, however, when moderate (slap, scratch, physically twisted their arm, bent back their fingers, pushed, grabbed, shoved, or kicked them) and severe (hit with a fist or something else hard, beat up, assault with a knife or gun) dating violence were examined. In the DV Only profile, there were no sex differences in the amount of moderate dating violence perpetrated, but boys reported perpetrating significantly more severe dating violence than girls $(\mathrm{t}=2.19, \mathrm{p}=.04)$. Likewise, in the PV Only profile, there were no sex differences in the amount of moderate peer violence perpetrated, but boys reported perpetrating significantly more severe peer violence than girls $(t=2.19, \mathrm{p}=.04)$. However, in the Both profile, boys reported perpetrating significantly more moderate $(\mathrm{t}=6.89 ; \mathrm{p}<$. $001)$ and severe $(t=8.20 ; p<.001)$ dating violence than girls and significantly more moderate $(\mathrm{t}=4.87 ; \mathrm{p}<.001)$ and severe $(\mathrm{t}=7.83 ; \mathrm{p}<.001)$ peer violence than girls.

\section{Risk and Protective Factors Distinguishing Profile Membership}

Table 3 presents the results from the final domain-specific multinomial models and Table 4 presents the results from the post-hoc analyses of significant interactions betweens sex and the risk and protective factors.

Distinguishing the Both profile from the DV Only profile-For both boys and girls having friends who perpetrate peer violence is associated with increased odds of using both types of violence compared to using dating violence only, but having friends who use dating violence is associated with decreased not increased odds of using both violence types. Having higher levels of individual social bonding is associated with decreased odds of using both violence types. The significant interaction between sex and peer social control indicates that for boys only increased peer social control is associated with decreased odds of using both violence types compared to dating violence only.

Distinguishing the Both profile from the PV Only profile-For both boys and girls, higher levels of depression, alcohol use, marijuana use, and neighborhood models of deviant behavior are associated with increased odds, and higher individual level social bonding is associated with decreased odds of using both violence types compared to using peer violence only. As shown in Table 4, significant interactions with sex indicate that although family conflict and school models of deviant behavior are significantly associated with increased odds of using both verses peer violence only for both boys and girls, those associations are stronger for boys. Likewise, although peer social control is significantly associated with decreased odds of using both types verses peer violence only for both boys and girls, that association is stronger for boys. For girls, school bonding is associated with significant decreased odds of using both types compared to peer violence only, but 
unexpectedly, for boys, school bonding is associated with significant increased odds of using both types compared to peer violence only.

Distinguishing the Both profile from the Neither profile-Many factors distinguish adolescents who use both compared to neither type of violence. For both boys and girls, as expected, higher levels of anger, anxiety, alcohol use, marijuana use, number of friends perpetrating peer violence, and neighborhood models of deviant behaviors are associated with increased odds, and higher levels of individual social bonding, parental monitoring, and neighborhood social control are associated with decreased odds of using both verses neither type of violence. The pattern of sex interactions distinguishing the Both from the Neither profile is similar to that distinguishing the Both from the PV Only profile in that family conflict, peer social control, and school deviant behaviors distinguish the profiles in expected directions for both males and females, but the associations are stronger for boys than for girls. For girls only, school bonding is associated with decreased odds of using both types of violence.

\section{Model Fit}

Based on the BIC and the pseudo $\mathrm{R}^{2}$, the individual domain model has the best relative fit, and the peer domain has the second best relative fit.

\section{DISCUSSION}

Consistent with adult studies, adolescents in the Both profile used more of each type of violence than those in the DV or PV Only profiles. As hypothesized, those in the Both profile had more maladaptive risk and protective scores than adolescents in the PV Only and Neither profiles. Most social learning theory risk factors and social control theory protective factors distinguished those profiles as did psychological attributes and substance use. Factors distinguishing profile membership were generally the same for boys and girls, though some associations were stronger for boys than girls; in general, peer social control was a stronger protective factor against and family conflict and school models of deviant behavior were stronger risk factors for using both types of violence for boys than girls. However, school bonding, was a stronger protective factor against using both types of violence for girls than boys. The individual attributes and behaviors and the peer context models fit the data the best. In addition, for all three violence profiles, boys as compared to girls reported using more violence and specifically more severe violence.

Very few of the risk and protective factors distinguished the Both from the DV Only profile. These findings contrast with those of others who found many differences between adult batters who used violence against only their partners and those who generalized their violence to others [2]. However, we do not have measures for several of the constructs that distinguished those two groups in prior adult studies such as attachment styles, jealousy, impulsivity, acceptance of partner violence, and hostility toward women. Also, power was likely lower for that contrast because of the very small percentage of adolescents in the DV Only profile. 
Two associations were in the direction opposite of that hypothesized. Having friends who perpetrate dating violence was associated with decreased, rather than increased odds of using both violence types verses dating violence only. Perhaps this finding reflects a basic social learning principle that modeling is often behavior specific. It may be that friend dating violence influenced adolescent modeling of dating violence but not peer violence, increasing the odds that adolescents with such exposures were in the DV Only rather than the Both profile. The second was that for boys, school bonding increased rather than decreased the odds of being in the Both compared to the PV Only profile. Perhaps the school bonding measure captured different aspects of the school environment for girls and boys. For boys, stronger school bonds may have indexed increased exposure to opportunities to interact with dates and peers, perhaps through involvement in school sports activities, and therefore increased the risk of involvement in both dating and peer violence. It may also be that for boys, but not for girls, the school bonding measure indexed an antisocial rather than a prosocial bond. For example, for boys only involvement in some school activities (i.e., some types of sports or clubs) may provide a context in which violent behavior towards dates and peers is promoted rather than constrained. It is also possible that these two findings were due to chance alone.

Our findings concur with those of many other studies that physical violence against peers and dates by girls is prevalent [11]. Girls as compared to boys were twice as likely to be in the DV Only profile, and to be in the Both profile. However, it is important to note that within each profile, boys reported using significantly more violence, and specifically more severe violence, than girls. These findings concur with other studies that suggest that there are qualitative differences in the types of violence used by boys and girls, with boys using more severe types of violence than girls [27-29].

The limitations of the study are an inability to assess the temporality of relationships between the risk and protective factors and violence profiles, and the limited time frame (6 months) when behaviors were assessed, the latter of which could have resulted in some misclassification of adolescents into profiles. However, that kind of bias would tend to decrease the likelihood of finding factors that distinguish profiles, whereas we found many significant factors distinguishing profiles. Also, given our analytic strategy, we were unable to test for profile stability; some research has found that adult typologies of domestic violence are not stable over time $[30,31]$.

The findings have many implications for developing interventions for preventing peer and dating violence. Currently, separate violence prevention programs are being implemented in schools and communities and with families to prevent peer and dating violence. In recent years, there has been a call for identifying common risk factors for multiple types of violence to promote more efficient violence prevention programming by developing single intervention approaches to prevent multiple forms of adolescent violence [32]. Our findings contribute to these efforts. Boys and girls who used both types of violence compared to neither type exhibited higher levels of anger and anxiety, used more alcohol and marijuana, and were exposed to more family, peer, school and neighborhood models of aggressive behaviors. They were also less bonded to society's conventional beliefs, were monitored less by their parents, experienced less peer social control, felt less bonded to the school (for girls 
only), and experienced less informal social control from their neighbors. Targeting each of these factors for change could lead to the prevention of both peer and dating violence for both boys and girls. Almost all currently used family- and school-based peer violence and dating violence prevention curricula include multiple sessions that target a variety of risk factors for change [33-35]. This study informs the selection of risk factors that could be targeted for change in a single family- or school-based curriculum. The findings also demonstrate a need to incorporate intervention components at multiple levels of the socioecological framework in order to prevent both peer and dating violence.

\section{Acknowledgments}

This research was funded by the National Institute on Drug Abuse (R01 DA16669) and the Centers for Disease Control and Prevention (R49 CCV423114).

\section{REFERENCES}

1. Langhinrichsen-Rohling J, Huss MT, Ramsey S. The clinical utility of batterer typologies. Journal of Family Violence. 2000; 15:37-53.

2. Holtzworth-Munroe A, Meehan JC, Herron K, et al. Testing the Holtzworth-Munroe and Stuart (1994) batterer typology. J Consult Clin Psychol. 2000; 68:1000-1019. [PubMed: 11142534]

3. Waltz J, Babcock JC, Jacobson NS, Gottman JM. Teesting a typology of batterers. Journal of Consulting and Clinical Psychology. 2000; 68:658-669. [PubMed: 10965641]

4. Jacobson, N.; Gottman, J. When men batter women: New insights into ending abusive relationships. New York: Simon \& Schuster; 1998.

5. Shields NM, McCall GJ, Henneka CR. Patterns of family and nonfamily violence: Violent husbands and violent men. Violence Vict. 1988; 3:83-97. [PubMed: 3154176]

6. White RJ, Gondolf EW. Implications of personality profiles for batterer treatment. Journal of Interpersonal Violence. 2000; 15:467-488.

7. Holtzworth-Munroe A, Meehan JC. Typologies of men who are maritally violent: Scientific and clinical implications. Journal of Interpersonal Violence. 2004; 10:1369-1388. [PubMed: 15492053]

8. Gorman-Smith D, Tolan PH, Shiedow AJ, et al. Partner violence and street violence among urban adolescents: Do the same family factors relate? J Res Adolesc. 2001; 11:273-295.

9. Bossarte RM, Simon TR, Swahn MH. Clustering of adolescent dating violence, peer violence, and suicidal behavior. Journal of Interpersonal Behavior. 2008; 23:815-833.

10. Farrell AD, Kung EM, White KS, et al. The structure of self-reported aggression, drug use, and delinquent behaviors during early adolescence. J Clin Child Psychol. 2000; 29:282-292. [PubMed: 10802836]

11. Foshee, VA.; Matthew, R. Adolescent dating abuse perpetration: A review of findings, methodological limitations, and suggestions for future research. In: Flannery, D.; Vazonsyi, A.; Waldman, I., editors. The Cambridge Handbook of Violent Behavior and Aggression. New York: Cambridge University Press; 2007. p. 431-449.2007

12. Pepler, DJ.; Craig, WM. Aggressive girls on troubled trajectories: A developmental perspective. In: Pepler, DJ.; Madsen, KC.; Webster, C., et al., editors. The development and treatment of girlhood aggression. Mahwah, NJ: Lawrence Erlbaum Associates; 2005. p. 3-28.

13. Bandura, A. Social learning theory. Englewood Cliffs, NJ: Prentice-Hall; 1977.

14. Elliott, DS.; Huizinga, D.; Ageton, SS. Explaining delinquency and drug use. Beverly Hills, CA: Sage Publications; 1985.

15. Hirschi, T. Causes of delinquency. Berkeley, CA: University of California Press; 1969.

16. Hill KG, Hawkins JD, Catalano RF, Abbott RD, Guo J. Family influences on the risk of daily smoking initiation. Journal of Adolescent Health. 2005; 37(3):202-210. [PubMed: 16109339]

17. Akers RL, Krohn MD, Lanza-Kaduce, et al. Social learning and deviant behavior: A specific test of a general theory. American Sociological Review. 1979; 44:636-655. [PubMed: 389120] 
18. Battistich V, Hom A. The relationship between students' sense of their school as a community and their involvement in problem behaviors. American Journal of Public Health. 1997; 87:1997-2001. [PubMed: 9431290]

19. Sampson RJ, Raudenbush SW, Earls F. Neighborhoods and violent crime: A multilevel study of collective efficacy. Science. 1997; 277:918-924. [PubMed: 9252316]

20. Tschann JM, Flores E, Pasch LA, et al. Emotional distress, alcohol use and peer violence among Mexican-American and European-American adolescents. J Adolesc Health. 2005; 37:11-18. [PubMed: 15963902]

21. Office of the Surgeon General. Youth Violence: A Report of the Surgeon General [Online]. Available at: http://www.surgeongeneral.gov/library/youthviolence.

22. Magdol L, Moffitt TE, Caspi A, et al. Gender differences in partner violence in a birth cohort of 21-year-olds: bridging the gap between clinical and epidemiological approaches. J Consult Clin Psychol. 1997; 65:68-78. [PubMed: 9103736]

23. Foshee VA, Linder F, MacDougall JE. Gender differences in the longitudinal predictors of dating violence. Prev Med. 2001; 32:128-141. [PubMed: 11162338]

24. Foshee V. Gender differences in adolescent dating abuse prevalence, types, and injuries. Health Education Research. 1996; 11(3):275-286.

25. SAS Institute. Statistical Analysis Software (SAS), Version 9.1. Cary, NC: SAS Institute, Inc.; 2003.

26. Allison, PD. Missing data. Thousand Oaks, California: Sage Publications; 2000.

27. Foshee VA, Benefield T, Suchindran C, Ennett ST, Bauman KE, Karriker-Jaffe KJ, McNaughton Reyes HL, Mathias J. The development of four types of adolescent dating abuse and selected demographic correlates. Journal of Research on Adolescence. 2009; 19(3):380-400.

28. O’Leary KD, Slep AMS, Avery-Leaf A, Cascardi M. Gender differences in dating aggression among multiethnic high school students. Journal of Adolescent Health. 2008; 42:473-479. [PubMed: 18407042]

29. Munoz-Rivas MJ, Grana JL, O’Leary KD, Gonzalez MP. Aggression in adolescent dating relationships: Prevalence, justification, and health consequences. Journal of Adolescent Health. 2007; 40:298-304. [PubMed: 17367721]

30. Capaldi DM, Kim HK. Typological approaches to violence in couples: A critique and alternative conceptual model. Clinical Psychology Review. 2007; 27:253-265. [PubMed: 17084496]

31. Langhinrichsen-Rohling J. Controversies involving gender and intimate partner violence in the United States. Sex Roles. 2010; 62:179-193.

32. National Center for Injury Prevention and Control. CDC injury research agenda. Atlanta: Centers for Disease Control and Prevention; 2002.

33. Foshee VA, Bauman KE, Ennett ST, Suchindran C, Benefield T, Linder GF. Assessing the effects of the dating violence prevention program "Safe Dates" using random coefficient regression modeling. Prevention Science. 2005; 6(3):245-258. [PubMed: 16047088]

34. Wolfe DA, Crooks C, Jaffe P, Chiodo D, Hughes R, Ellis W, Stitt L, Donner A. A school-based program to prevent adolescent dating violence. Archives of Pediatric Medicine. 2009; 163:692699.

35. Szapocznik J, Williams RA. Brief strategic family therapy: twenty-five years of interplay among theory, research and practice in adolescent behavior problems and drug abuse. Clinical Child and Family Psychology Review. 2000; 3(2):117-134. [PubMed: 11227062]

36. Zuckerman, M.; Lubin, B. Manual for the Multiple Affect Adjective Check List - Revised. San Diego, California: Educational and Industrial Testing Service; 1985.

37. Reynolds CR, Richmond BO. Factor structure and construct validity of "What I Think and Feel": The Revised Children's Manifest Anxiety Scale. J Pers Assess. 1979; 43:281-283. [PubMed: 469706]

38. Angold A, Costello EJ, Messer SC. Development of a short questionnaire for use in epidemiological studies of depression in children and adolescents. International Journal of Methods in Psychiatric Research. 1995; 5:237-249.

39. Bloom BL. A factor analysis of self-report measures of family functioning. Family Process. 1985; 24(2):225-239. [PubMed: 4018243] 
40. Jackson C, Henriksen L, Foshee VA. The Authoritative Parenting Index: Predicting health risk behaviors among children and adolescents. Health Educ Behav. 1998; 25:319-337. [PubMed: 9615242] 


\section{Table 1}

Measures of risk (RF) and protective factors (PF).

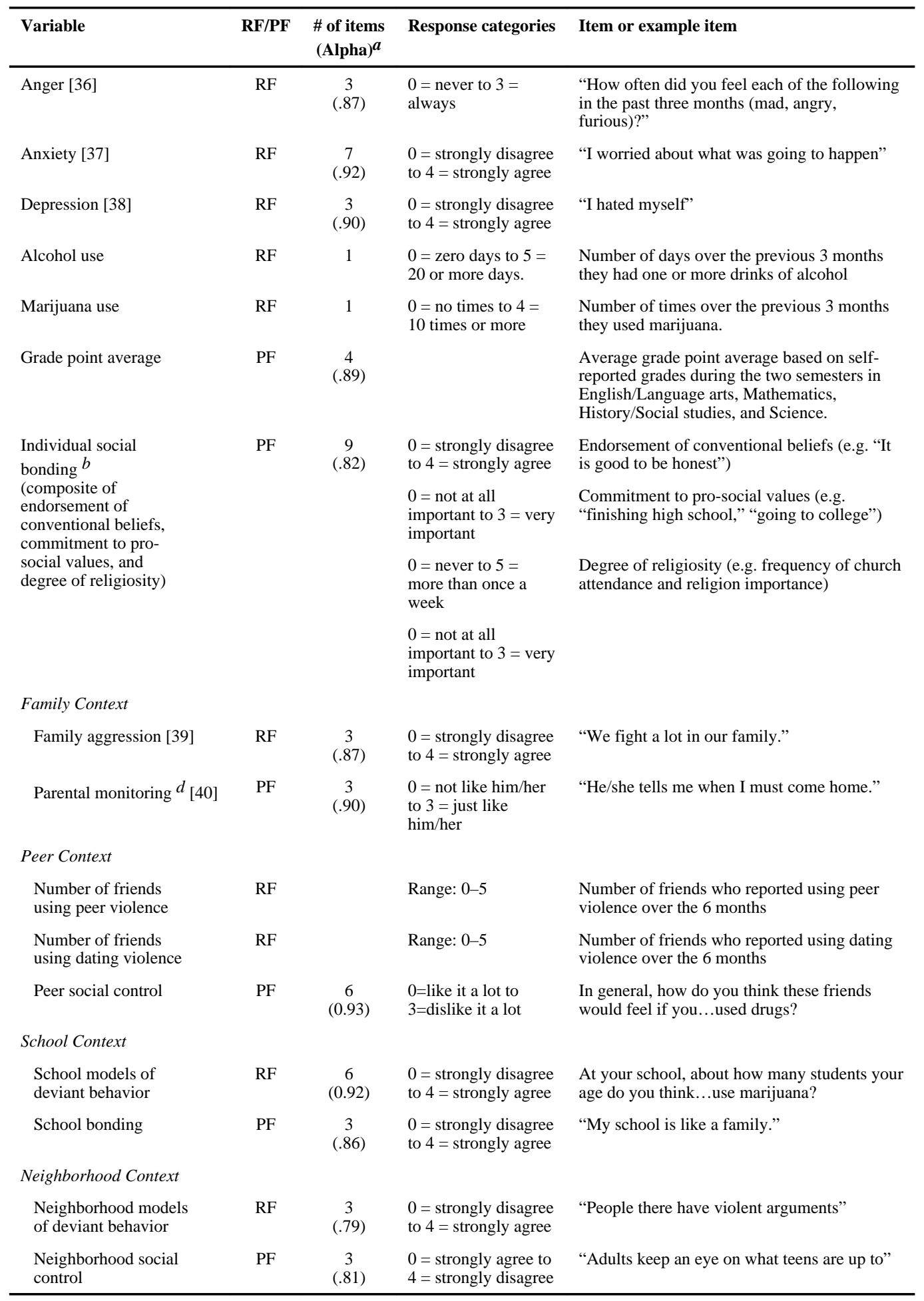


Note. For all domains, items were assessed at the fall assessment and at the spring assessment, and responses were summed across the two assessments to produce a single score assessing beliefs and behaviors over 6 months.

${ }^{a}$ Cronbach's alpha provided for scale measures formed by three or more items.

${ }^{b}$ Each subscale was standardized before summing to create the social bonding composite measure.

${ }^{c}$ Peer context variables were created using sociometric data.

$d_{\text {If two parents were in the household, the highest value of the two parents was used. }}$ 


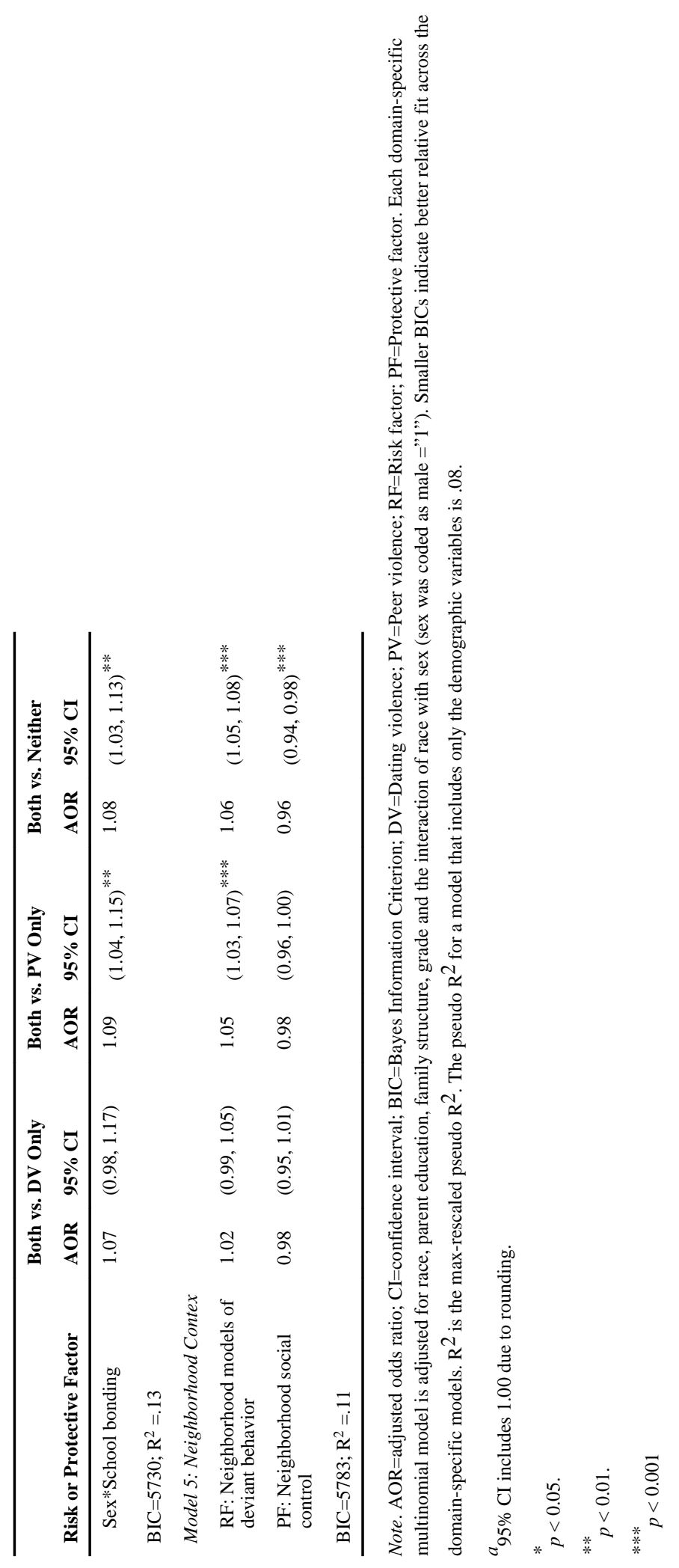


